\title{
Morphology and geometry of Valles Marineris landslides
}

\author{
C. Quantin*, P. Allemand, C. Delacourt \\ Université Claude Bernard Lyon-1 \& ENS Lyon, Laboratoire Sciences de la Terre, UMR 5570 CNRS, Bat géode-6e étage, 2 rue Raphaël Dubois, \\ 69622 Villeurbanne Cedex, France
}

\begin{abstract}
The walls of the Valles Marineris canyons are affected by about 45 landslides. The study of these landslides provides a test of the hypothesis of processes having affected Martian wallslopes after their formation. The dynamics of Valles Marineris landslides are controversial : either the landslides are interpreted as large debris flows or as dry rock avalanches. Their morphology and their topography are basic parameters to understand their dynamics. From topographic MOLA data and remote sensing images acquired with different spatial resolutions (Viking, THEMIS, MOC), the 3D geometry of 45 landslides of Valles Marineris has been studied. The landslides have been classified in 3 geomorphologic classes from the topography of the landslide deposits: the "chaotic" landslides without well identified structures, the "structured deposit without debris aprons" landslides with tectonic structures and small roughness at the deposit front and the "structured deposit with debris aprons" which display circular normal faults at the back of the deposit and several debris aprons at the front of the landslide. The spatial distribution of the three morphological types is in relation with the confinement of the canyons. The initial volume and the total deposited volume were also measured to compute volume balances. The deposited volumes range from 50 to $5000 \mathrm{~km}^{3}$. All volume balances display a maximum deficit ranging from $5 \%$ to $70 \%$. The landslides with the largest deficits take place within an enclosed-canyon (Hebes Chasma). Lacking material exportation, these deficits could be interpreted as reflecting the porosity of the landslide source. This fact is in agreement with the hypothesis of a karstic origin of these enclosed-canyons. The Valles Marineris landslides have large mobilities (length/vertical drop) ranging from 1.8 to 12 implying low coefficients of friction and so fluidization mechanisms. The possible filling up of the porosity by volatile could be compatible with the fluidization patterns of Valles Marineris landslides.
\end{abstract}

Keywords: Landslide; Mars; Morphology

\section{Introduction}

Martian wallslopes are affected by numerous landslides especially within Valles Marineris (V.M). The analysis of these Martian morphologies permits first to study gravitational processes under different gravities and secondly to test the hypothesis of processes that affected Martian wallslopes after their formation. The landslides of Valles Marineris discovered with Viking pictures were initially interpreted as large wet debris flows implying the intervention of water in order to

\footnotetext{
*Corresponding author. Tel.: + 33-4-72-44-62-40; fax: + 33-4-72-4485-93.

E-mail address: cathy.quantin@univ-lyon1.fr (C. Quantin).
}

explain the mobility (ratio between the length of the landslide and the vertical drop) of these landslides and the interactions between landslides and water-worn morphologies (Lucchitta, 1978, 1979, 1987). In contrast to this interpretation, a second study has found that the mobilities of Valles Marineris landslides are analogous to dry terrestrial rock avalanches (McEven, 1989). The role of fluids in the Martian landslide dynamics is not unanimously admitted yet. More than the dynamics of the landslide events, the dynamics of their initiation is unknown. On Earth, these processes are related to ground conditions within the wallslopes for the intrinsic factors and to the climate or the seismicity for the external factors. The topographic data of Mars Orbiter Laser Altimeter (MOLA) and the high spatial resolution 
images acquired by Mars Orbiter Camera (MOC) from Mars Global Surveyor (MGS) permit a new analysis of the final geometry of Valles Marineris landslides. We present the results of a multidisciplinary study of landslide morphology and geometry using images with different spatial resolutions and altimetric data. These results allow us to propose hypothesis about the ground conditions of Valles Marineris wallslope at landslide time.

\section{Geological setting and data set}

\subsection{Valles Marineris}

Valles Marineris is a $4000 \mathrm{~km}$ long east-west trough system located in the equatorial zone of Mars on the eastern flank of the Tharsis zone. The width of the canyon ranges from $50 \mathrm{~km}$ to more than $500 \mathrm{~km}$ in the central part of Valles Marineris. Width variations could correspond to rock strength variations relative to the erosional process (McCauley, 1978). The walls of the canyon, which have an average slope of $20^{\circ}$, are shaped by normal fault with $6 \mathrm{~km}$ of throw (Banerdt et al., 1992). Triangular faceted spurs are visible on the walls of the canyon and indicate that the faulting is important to the origin of the canyon. The initiation of tectonics has been dated from the Hesperian period (Head et al., 2001).

The morphology of the canyons has been modified by external processes like gravitational mechanisms and fluvial events, which have contributed to the present morphology after the tectonic episode (Peulvast et al., 2001). The existence of water in the Valles Marineris area is demonstrated by the presence of lobate ejecta craters in the neighboring zones such as Lunea Planum or Sinai Planum. These craters indicate the existence of fluids at the time of impact in the upper part of the crust to around $5 \mathrm{~km}$ depth (Boyce et al., 1996).

The trough system also displays a completely enclosed canyon, Hebes Chasma. Layered deposits within the enclosed canyon suggest emplacement in covered lakes (Nedell and Squyres, 1987). This enclosed troughs could have been originated by thermokarstic or karstic processes (Spencer and Fanale, 1990; Carr, 1996).

\subsection{Data sets}

Forty-six landslides were identified and mapped on Viking Orbiter images (Table 1). The boundaries of landslide deposits were defined on the Viking Orbiter images, on the available MOC images and with Digital Elevation Models (DEM) derived from the interpolation of MOLA profiles. Spatial resolution of MOLA data is $300 \mathrm{~m}$ along the profiles and around $2 \mathrm{~km}$ between two profiles in Valles Marineris (Smith et al., 2001), the vertical accuracy is few meters. The quality of DEM is better North-South than East-West because of the polar orbit of the MGS probe. As the walls of Valles Marineris are roughly East-West, the flow of landslides has been mainly in N-S direction. So, MOLA DEM's are accurate to study geometrical parameters of the landslides (Table 1), especially along profiles realized on the DEM.

\section{Characteristics of Valles Marineris landslides}

Valles Marineris landslides are prominent features because the landslides scarps affect all the wallslopes and form re-entrants in the neighboring plateau of Valles Marineris. The dimensions of the landslides are one order in magnitude larger than terrestrial ones. The average deposit area is $938 \mathrm{~km}^{2}$, their average length $36 \mathrm{~km}$, their width $32 \mathrm{~km}$ (Table 1). The average vertical drop is $6 \mathrm{~km}$. Those values are not observed on Earth excepted in submarine slides. However, the relationships between geometrical parameters of Valles Marineris landslides are the same as for terrestrial ones despite the scale difference (Legros, 2002). The thickness of the landslide deposits decreases from about $2 \mathrm{~km}$ at the foot of the scarp to $100 \mathrm{~m}$ at the front of the landslide. The surface of the landslide deposit is characterized by a hectometric scale roughness, which is observed on the Viking images and topographic profiles.

In this section, the particular features of Valles Marineris landslides are described. A classification of Valles Marineris landslides based on the morphology of their deposits is proposed. The distribution of the different types within Valles Marineris is then studied. The volumes of the landslides are presented and volume balances between the landslide deposits and source areas are discussed. Finally, an analysis of the landslide dynamics is presented based on mobility measurement and comparison with terrestrial landslides.

\subsection{Classification of Martian landslides from their morphology}

A landslide classification is proposed according to the morphological and topographic features of the landslide deposits. Four morphological types are defined: (1) chaotic (C), (2) structured deposit without debris aprons (SD), (3) structured deposit with debris aprons (SDWDA) and (4) hanging (H).

(1) The $\mathrm{C}$ type (11 landslides) displays rough deposits without well-identified tectonic structures (Fig. 1). The amplitude of the roughness could reach $1 \mathrm{~km}$ (Fig. 1) and the roughness is not organized. The deposits sometimes display some local linear topographies parallel to the landslide scarp but these topographies are not continuous along the width of the landslide. 


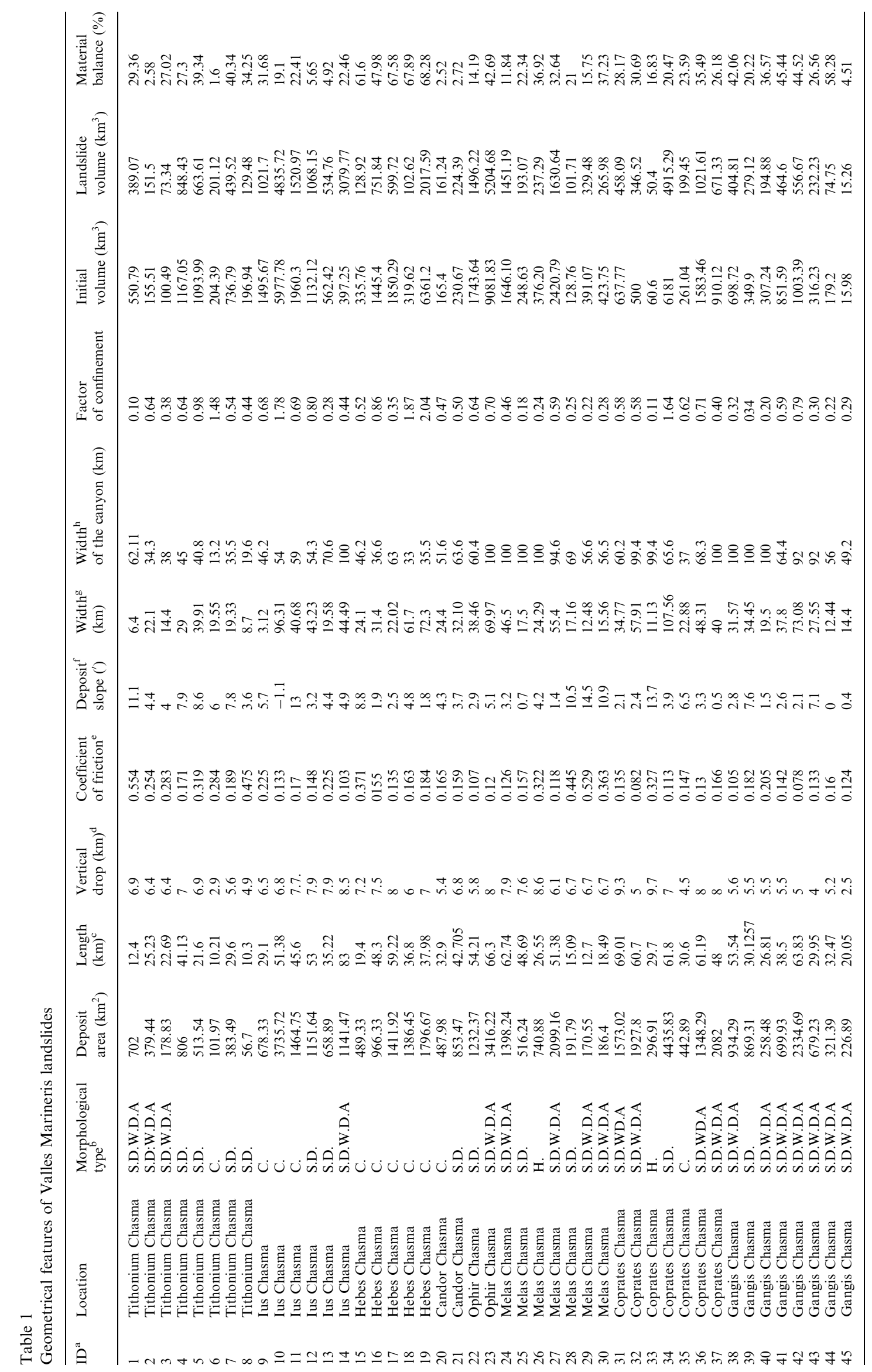

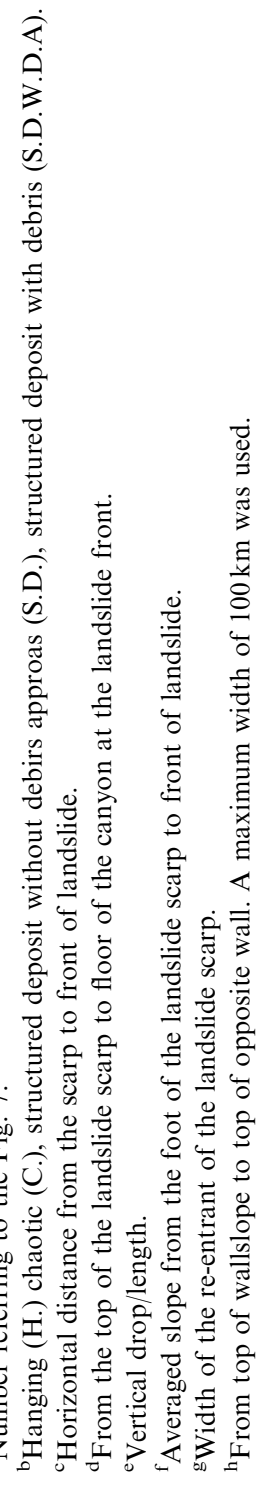



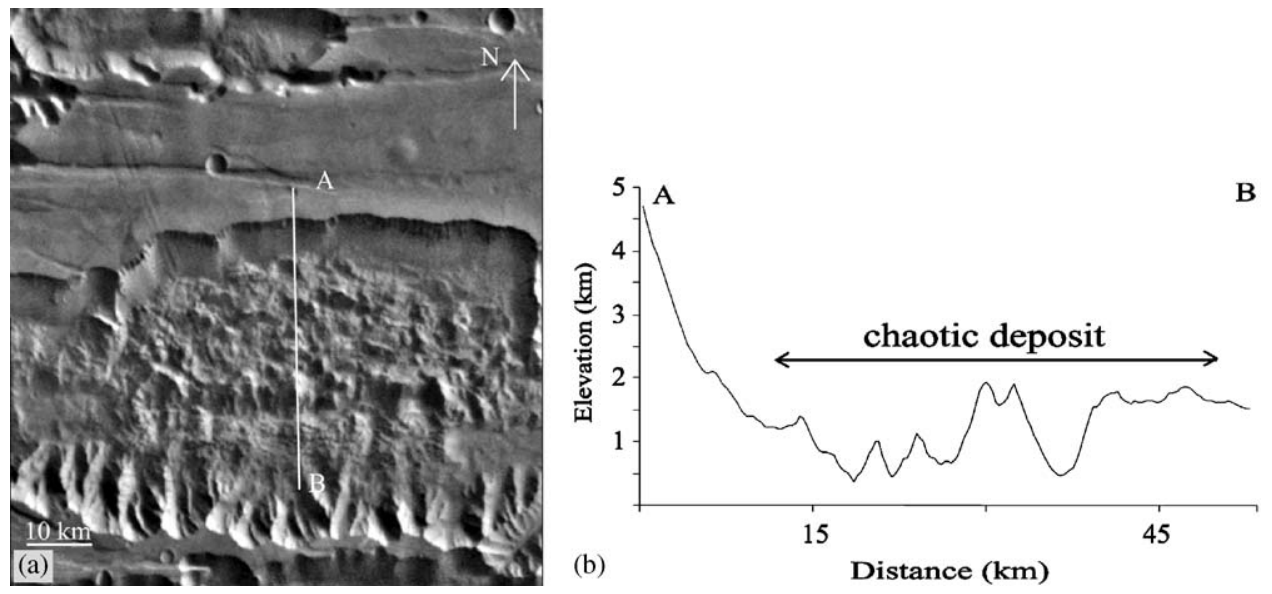

Fig. 1. Morphological features of the chaotic type (C): (a) Viking environment of the example (landslide in Ius Chasma no 10, Table 1) and location of the profile A-B. (b) Topographic profile A-B. The landslide deposit fills up the whole canyon and covers the lower part of the opposite wall.
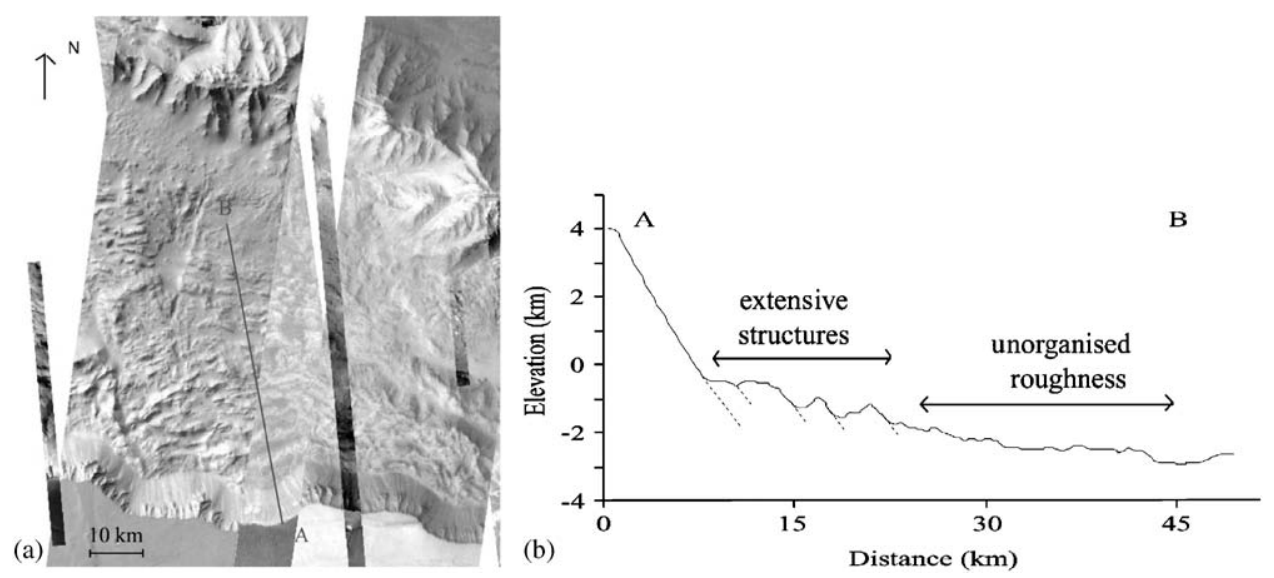

Fig. 2. Morphological features of the structured deposit without debris apron (SD) type: (a) Part of day time THEMIS (Mars Odyssey Mission) mosaic (landslide in Coprates Chasma no 34, Table 1) and location of the profile A-B. (b) Topographic profile A-B. Notice the extensive structures at the back of the landslide deposit and the unorganized roughness at the toe.

(2) The structured deposits without debris aprons (SD) type (12 landslides) display tectonic structures at the back of the deposit whereas the front shows unorganized roughness (Fig. 2). Indeed, the topographies located at the back of the landslide result from normal fault structures like often observed on terrestrial landslide areas. The distal part of the deposit is affected by small-scale roughness in order to $100 \mathrm{~m}$ in height.

(3) The structured landslides with debris aprons (SDWDA) type (20 landslides) also shows well-identified extensive structures at the back of the deposit whereas the main part of the deposit consists of large debris aprons (Fig. 3). The structures of the back part correspond to circular normal faults (Fig. 4) well observed on available MOC images crossing this kind of landslide (Fig. 4). The distal and main parts of the deposit are constituted by one or more large debris aprons. These debris aprons show longitudinal ridges observed in details on high-resolution images (Fig. 4). These morphologies would result from high velocity mechanisms (Shreve, 1966; Lucchitta, 1979). The debris aprons that are visible on DEM (Fig. 5) have a lobate shape and a thickness of $200 \mathrm{~m}$. The emplacement of these debris aprons occurs at high velocities because they sometimes overlap other aprons. For example, the landslide of Fig. 6 coming from the north wall overlaps an other $200 \mathrm{~m}$ high apron. According to Chow's potential energy equation (Chow, 1959), this run up of $200 \mathrm{~m}$ implies a velocity at least of $38 \mathrm{~m} / \mathrm{s}$.

(4) The hanging $(\mathrm{H})$ type (2 landslides) corresponds to landslides affecting only the upper part of the wallslope (Fig. 6). We note that the lower part of the wallslope 


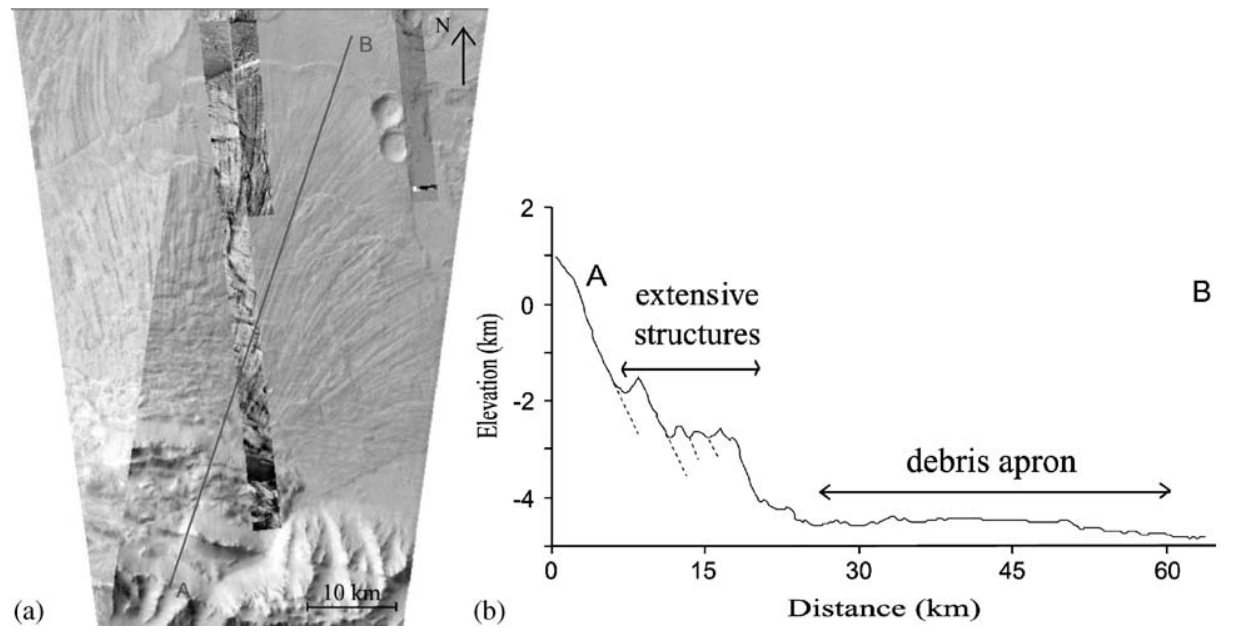

Fig. 3. Morphological features of the structured deposit with debris apron (SDWDA) type: (a) Part of day time THEMIS mosaic (landslide in Coprates Chasma no 42, Table 1) and location of the profile A-B. (b) Topographic profile A-B. Notice the extensive structures at the back of the landslide and the large debris apron at the toe.
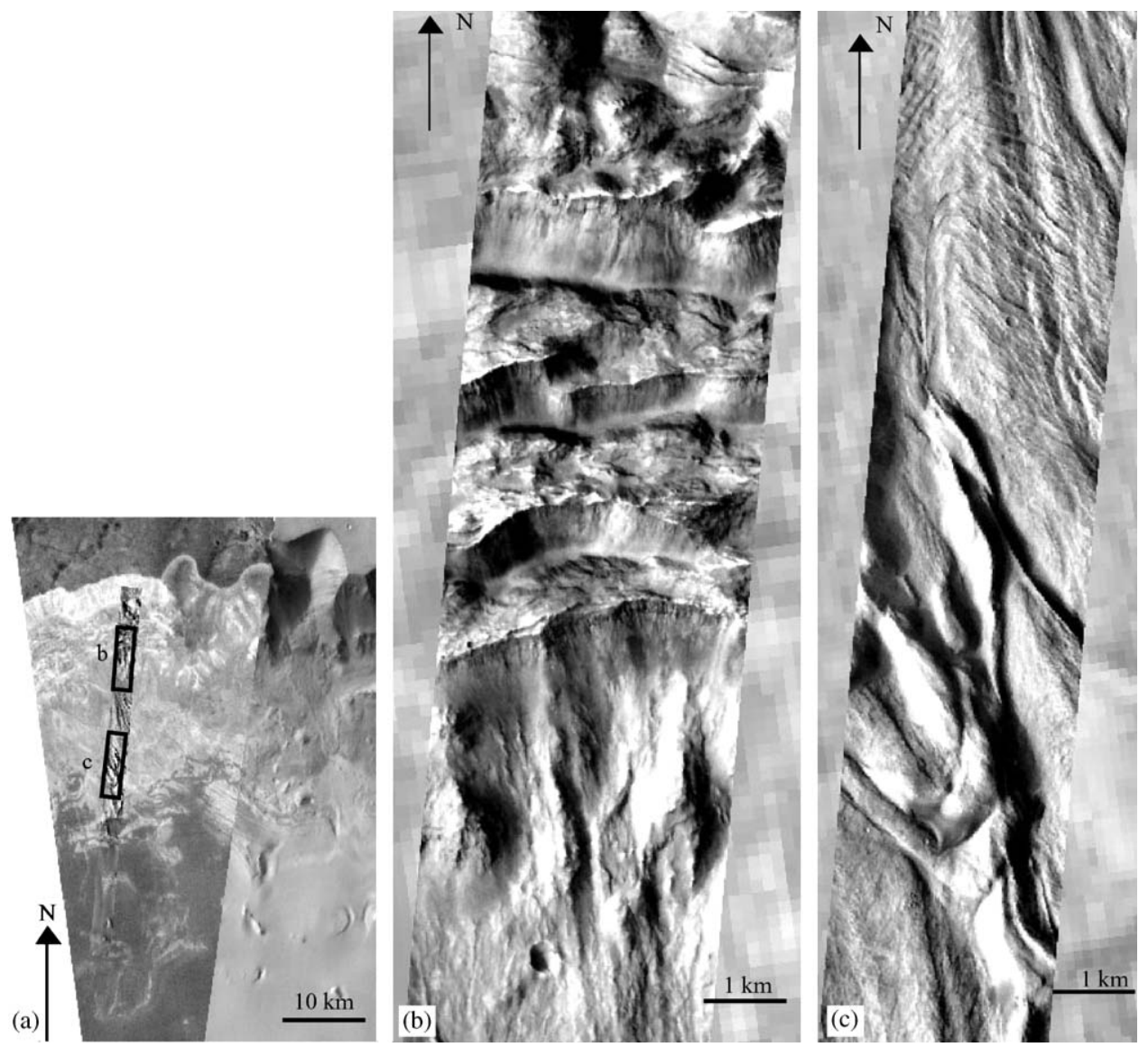

Fig. 4. Landslide deposit of the SDWDA type at high resolution: (a) Part of night time THEMIS mosaic (landslide no 39, Table 1): the landslide deposit is partly covered by dust in its distal part. (b) Part of MOC image no ab102802 covering the back part of the landslide deposit. (c) Part of MOC image no ab102802 covering the debris aprons.

displays spurs, gullies and triangular facets shaped during the tectonic formation of Valles Marineris. This kind of landslide either implies a middle slope discontinuity or a landslide emplacement before the end of the tectonic formation of the canyon allowing the later shaping of the lower part of the wallslope. Due to its poor representativeness, this kind of landslides was excluded from the following studies. 


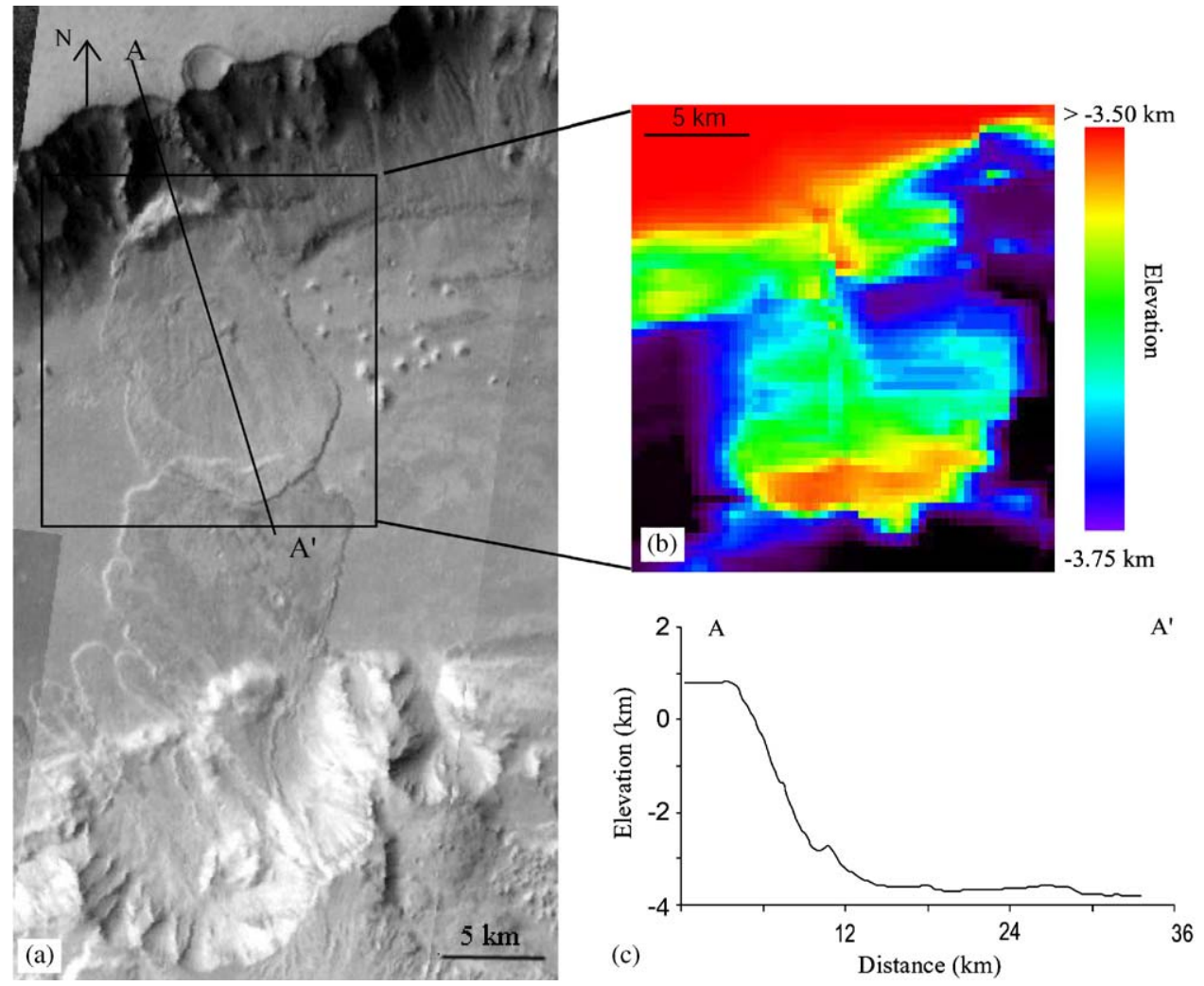

Fig. 5. Landslide debris aprons: (a) Part of day time THEMIS mosaic (landslide in Gangis Chasma no 45, Table 1) and location of the profile A-B. (b) DEM of the debris apron: the thickness of the deposit is about $200 \mathrm{~m}$. (c) Topographic profile A-B. The landslide coming from the north wall overlaps another debris apron coming from the south wall.
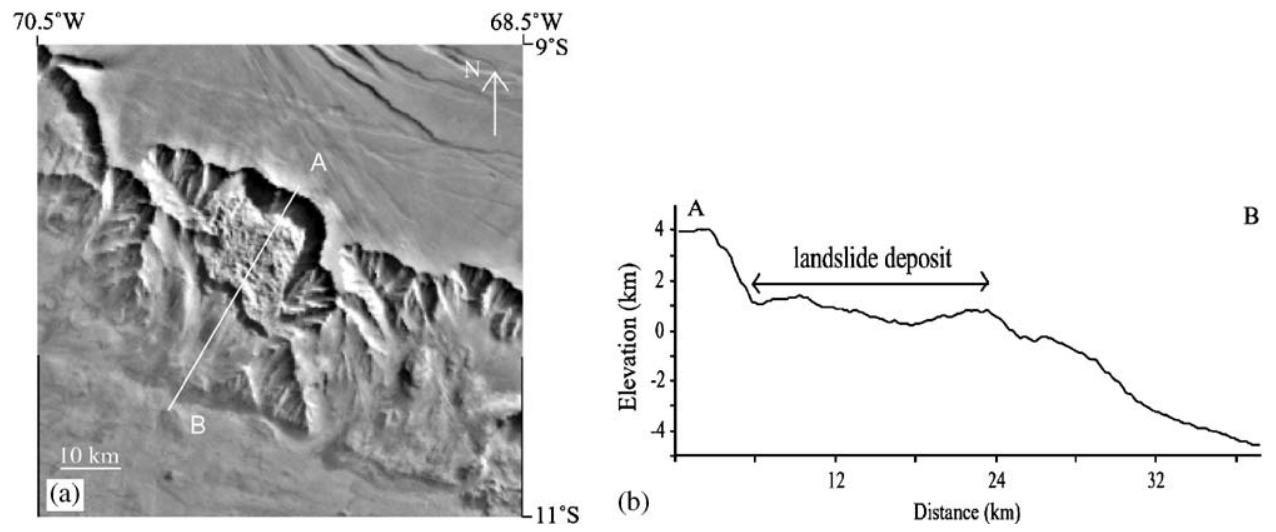

Fig. 6. Morphological feature of the H-type: (a) Viking environment of the example (landslide in Coprates Chasma no 26, Table 1) and location of the profile A-B. (b) Topographic profile A-B. The slope of the landslide scarp is larger than the slope of the basal part of the wallslope unaffected by the landslide which corresponds to the average slope of Valles Marineris wallslopes.

\subsection{Distribution of morphological types within Valles Marineris}

The landslides are located in all main open canyons of Valles Marineris and within enclosed canyons like Hebes Chasma. The spatial distribution of the morphological types of landslides is shown on the Fig. 7. The $\mathrm{C}$ landslides are mainly located within narrow canyons like
Ius Chasma and in the enclosed Hebes Chasma. The SDWDA landslides are mainly located in Gangis Chasma and on the walls of the central parts of Valles Marineris. The SD landslides are distributed all over the Valles Marineris area without evident local concentrations. The distribution of $\mathrm{C}$ and SDWA types seems to be related to the width of the canyon where they are located. To test this hypothesis, a "factor of 


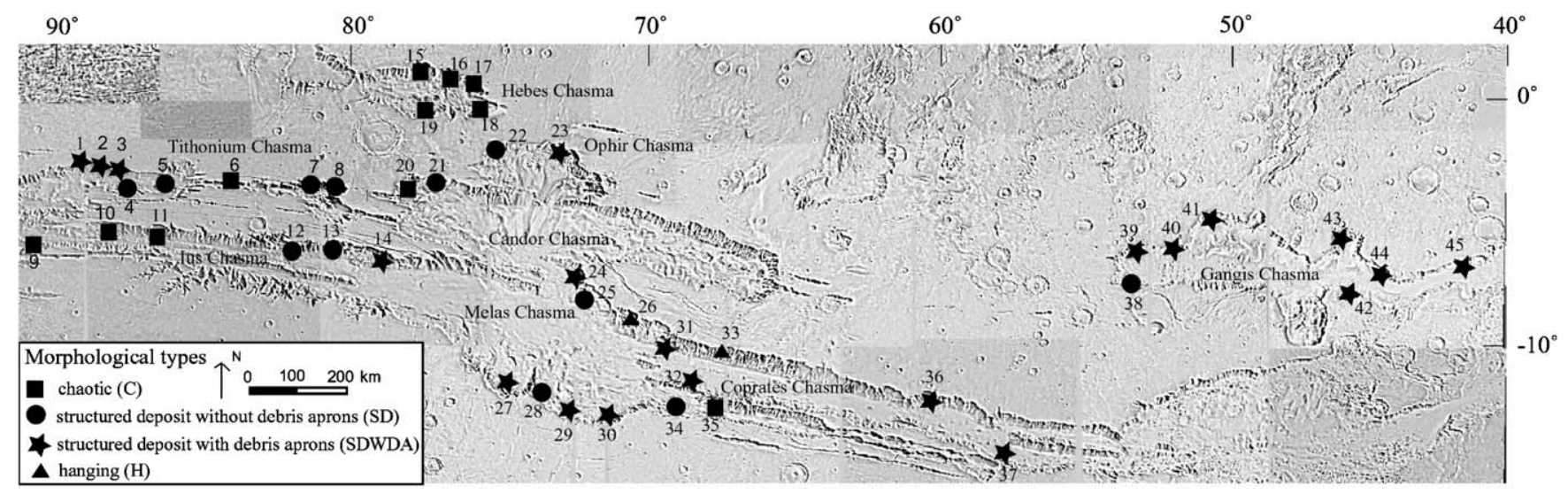

Fig. 7. Distribution of morphologic types within Valles Marineris. Numbers refer to the Table 1.

confinement" (FC) has been measured for each landslide. The $\mathrm{FC}$ is given by:

$\mathrm{FC}=$ Width of landslide scarp/Width of the canyon

This factor measures the ratio between the width of the landslide and the available space for the flow. On Earth, the geometrical parameters of landslides display scale-relation (Legros, 2002) so, in this study, the width of the landslides could be considered as a measure of their potential length. The value of the ratio between the length and the width of a terrestrial landslide is around 0.75 (from data of Morgan et al., 1997). If FC is under 0.75 , the length of the landslide is controlled by the width of the canyon instead of by the scale of the landslide.

Fig. 8 shows the frequency of the three morphological types for three classes of FC. The frequency of the SDWDA decreases for an increasing FC from $60 \%$ for the lower class of the FC $(<0.5)$ to lower than $5 \%$ for the upper class $(<0.75)$. The frequency of the SD decreases for an increasing FC from $50 \%$ for the lower class of the FC $(<0.5)$ to $25 \%$ for the upper class $(<0.75)$. In contrast, the frequency of the $\mathrm{C}$ type increases for an increasing F.C from $18 \%$ for the lower class to $45 \%$ for the upper class. So, the three morphological types are correlated with FC. Indeed, the $\mathrm{C}$ type corresponds to the larger $\mathrm{FC}$ values with an average of 1.03. This type of landslide occurs in confined environment according the ratio between the length and the width of terrestrial landslides. The SD type has a medium factor of confinement with an average of 0.6. This type of landslide corresponds to a middle type between the confined and the unconfined landslides. Lastly, the SDWDA types with an average factor of 0.44 are unconfined landslides.

Two assumptions can be proposed to explain the relation between the morphological type and the confinement of the landslide. The landslide typology

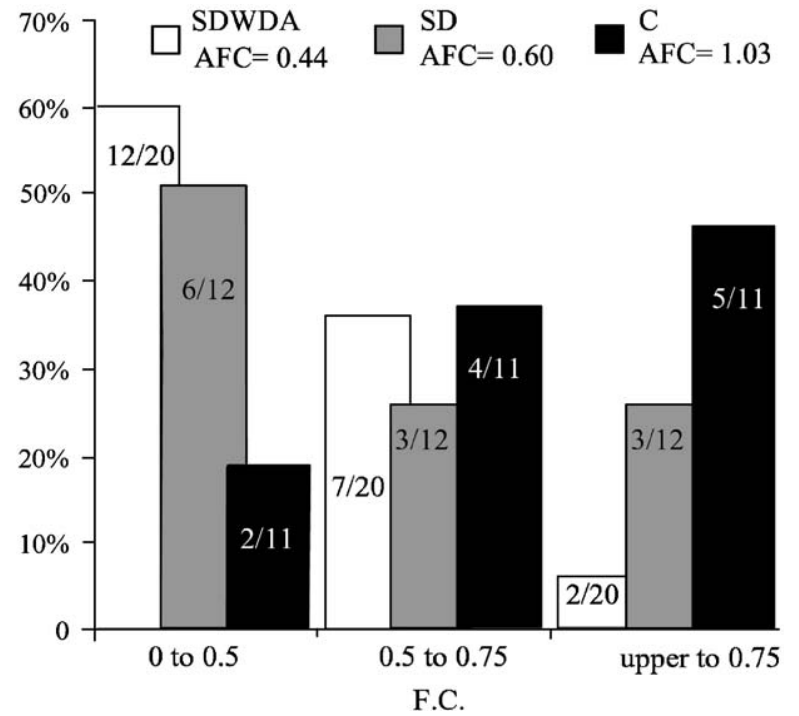

Fig. 8. Relationship between the three main morphologic types and the factor of confinement. The abscise axis correspond to three increasing classes of factor of confinement. The ordinate axis displays relative part in percent of the three landslide types. The relative part was computed from frequency of each type because they have different total populations. (AFC: Average Factor of Confinement).

could depend only on geometrical parameters of the canyon where the landslide flows. On Earth, the control of the shape of landslides by the local topography is observed (Nicoletti and Sorriso-Valvo, 1991). According to this assumption, all the landslides would then display debris aprons if they had enough space to flow. On the other hand, the local topography, particularly the width of the canyons like Melas Chasma and Ophir Chasma, seems to depend on the water content of the regolith (Peulvast et al., 2001). If a decrease of the width of canyon were related to a decrease of volatile amount, the three morphologic types would characterize three different volatile amounts. In this case, the existence of 
debris aprons could be controlled by the presence of fluids rather than the available space.

\subsection{Landslide volumes and volume balance}

The volume of about 30 landslides of Valles Marineris has been estimated by McEven (1989) from Viking data. For most of the landslides, the volumes were estimated from the volume of the void of the landslide scarp. For the others, the volumes were estimated from the surface of the deposit and the height at the deposit front. The volume of the landslides is smaller when estimated with the second method (Legros, 2002). Legros (2002) has suggested multiplying by 7 the volume estimated by this second method because the thickness at the toe of the deposit is not representative of the thickness of the whole deposit. The volumes of the 46 landslides of this study have been computed from topographic MOLA data.

The first step of volume estimation is the reconstruction of the pre-landslide geometry. Two reference topographic profiles were measured on each side of each landslide across unslided wallslopes (Fig. 9). Assuming that these unslided wallslopes were similar to the geometry of the landslide area before the landslide occurs, the pre-landslide geometry was constructed by the linear interpolation between these two profiles. In a second step, topographic profiles perpendicular to the landslide scarp were measured starting from the plateau to the toe of the landslide deposit. Then, These profiles were linearly interpolated. For most landslides, striking north-south, the spacing between the profiles for the interpolation was $300 \mathrm{~m}$ whereas this spacing for the several landslides with other orientation was $2 \mathrm{~km}$. In the third step, the DEM of the landslide has been subtracted to the DEM of the pre-landslide geometry in order to estimate the landslide volumes.

Two kinds of volumes have been computed in this way: the eroded volume which is under the pre-landslide surface and the settled volume, which is above (Fig. 9). The "filling up" volumes that correspond to the displaced material located under the pre-landslide surface has been modeled by a quarter of an ellipsoid. The three axes are the width of landslide scarp, the deposit thickness and the re-entrant length at the profiles crossing. The total deposited volume of the landslide is equal to the settled volume plus the "filling up" volume. The initial volume is equal to the eroded volume plus the "filling up" volume. The volume balance corresponds to the difference between the initial volume and the total deposited volume.

The errors in these volume estimations mostly depend on the exactness of the pre-landslide geometry. As a prelandslide geometry was defined from the local topographies of the hillslopes and canyon's floors close to every landslide, the errors related to the pre-landslide geome-
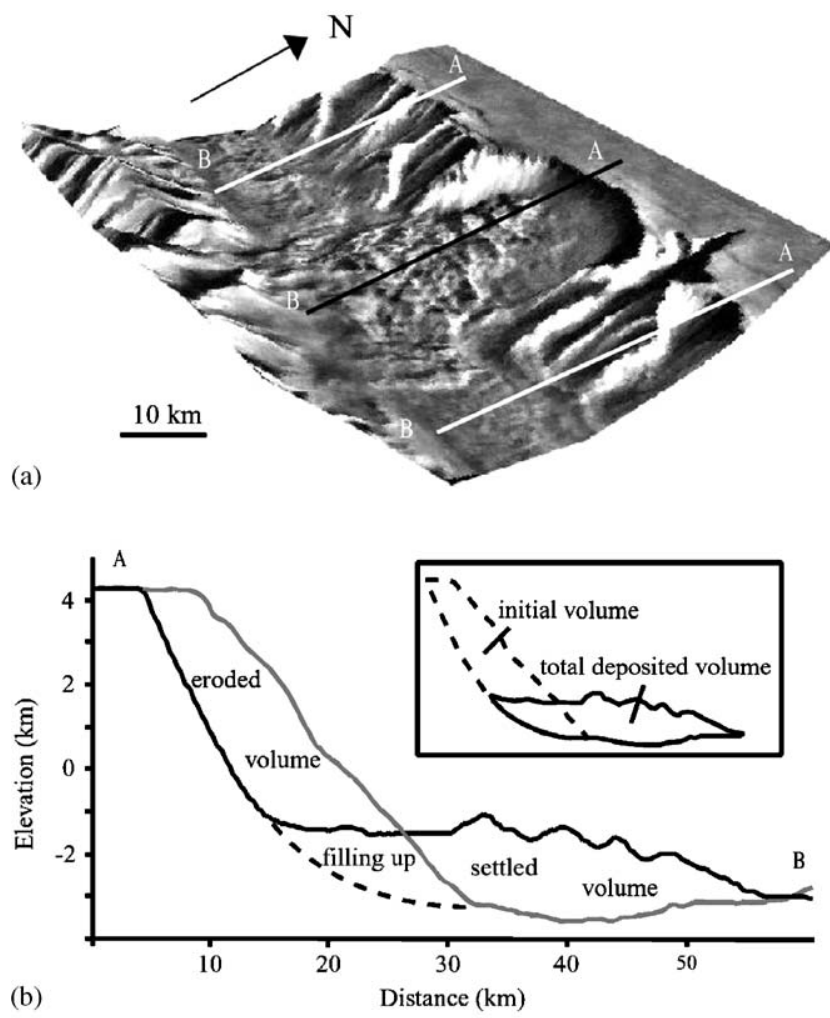

— across landslide — across unslided wallslopes

Fig. 9. Illustration of the computing Method of landslide volumes: (a) 3D surface view of a landslides area (Viking image overlapped on MOLA DEM). The black straight line corresponds to the topographic profile of the landslide area on the Fig. 9b and the white straight lines correspond to topographic profiles of unslided wallslopes on each side of the landslide area. (b) Overlap of two topographic profiles: the black one corresponds to the landslide areas and the Grey one is a linear interpolation of both white profiles of the Fig. 9a in order to obtain the pre-landslide geometry. The difference between both profiles corresponds to the eroded volume for the part under the pre-landslide surface and to the settled volume for the above part. The dotted line represents the part of deposited volume which is under the prelandslide profile (filling up volume).

try are limited. This pre-landslide geometry represents a maximum volume geometry because of the possible dissection of the wallslope before the landslide. The estimation of the "filling up" volume by an ellipsoid is a second source of error for both types of volume (initial and deposited). Indeed, the shape of the lower part of the landslide scarp is unknown because the deposit covers this zone. A quarter of ellipsoid gives a maximum value of this volume. The volume balance does not need the estimation of the "filling up" volume and is then more accurate.

The deposited landslide volumes range from 50 up to $5000 \mathrm{~km}^{3}$ (Table 1, Fig. 10). The initial volumes range between 60 and $9000 \mathrm{~km}^{3}$. The maximum values are three orders of magnitude larger than terrestrial landslides volumes, which reach $50 \mathrm{~km}^{3}$ (i.e. $50 \mathrm{~km}^{3}$ for the Gobi-Atlay sub-aerial landslide, Mongolia, Philip and 


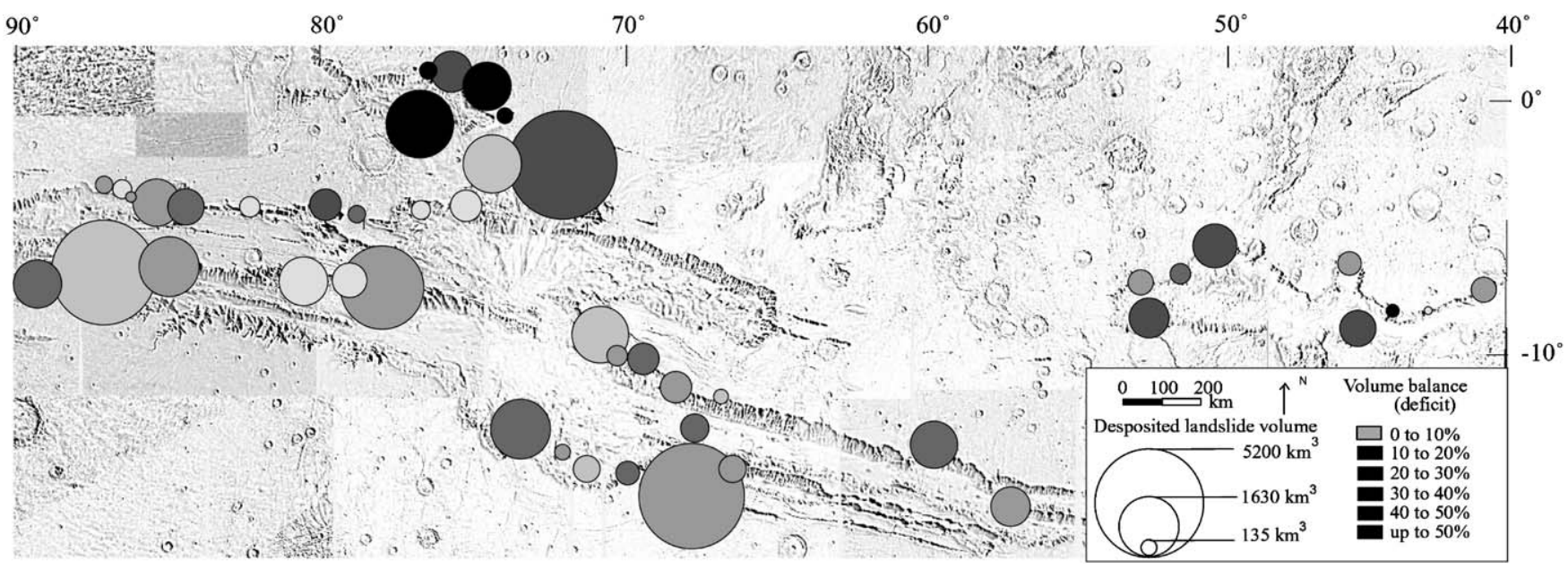

Fig. 10. Distribution of the volumes and material balances within Valles Marineris. The areas of the circles are proportional to the settled volumes. Grey levels correspond to increasing classes of material deficit.

Ritz, $1999,14 \mathrm{~km}^{3}$ for Traenadjupet submarine slide, Laberg and Vorren, 2000). This observation can be explained by the lower gravity on Mars than on the Earth, which favors the existence of high wallslopes such as those of Valles Marineris which are in average $6 \mathrm{~km}$ high.

The distribution of the landslide volumes within Valles Marineris is independent from the distribution of the landslides and from the morphological type.

The volume balances display deficits ranging from 5\% for the more equilibrated balances up to $70 \%$ for the largest deficits. The landslides with the largest volume deficits are located in Hebes Chasma (Fig. 10). All the five landslides of this canyon have a material deficit larger than $50 \%$. Hebes Chasma is an enclosed canyon where material exportation after the landslide is not possible. The other large deficits locate within Ophir and Gangis Chasma (Fig. 10). Ophir and Gangis Chasma are also both semi-enclosed canyons with a possible karstic origin (Carr, 1996; Spencer and Fanale, 1990).

\subsection{Mobility of Martian landslides}

The mobility of landslides is measured by the ratio between the runout of the landslide and the vertical drop. This ratio is directly related to the coefficient of friction of landslides (ratio between vertical drop and length) (Legros, 2001). The coefficient of friction of most dry rocks is 0.6. The coefficients of friction of terrestrial rock avalanches range from 0.1 to 0.3 (Fig. 11) whereas the coefficients of the saturated landslides are lower than 0.1 and about 0.01 for the submarine landslides (Legros, 2002). The mobility of the terrestrial rock avalanches have been explained by four hypothesis: (1) sliding on a layer of trapped air (Shreve, 1966), (2) presence of a basal layer of melted ice (Hewitt, 1988), (3) fluidization due to effects of low amounts of

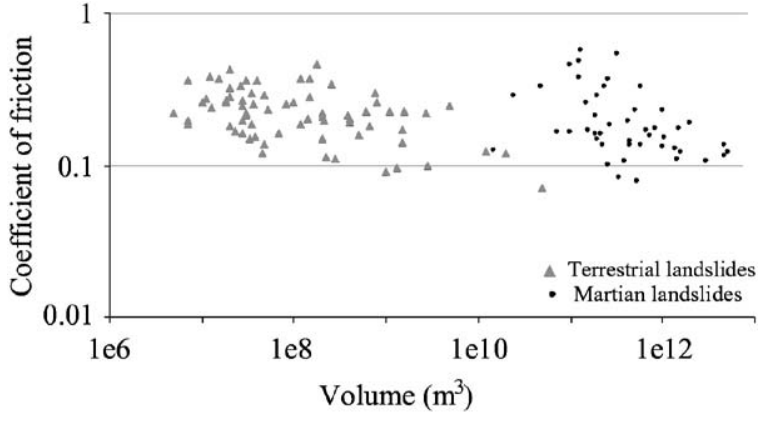

Fig. 11. Relationships between volume and coefficient of friction for terrestrial rock avalanches and Martian landslides (Table 1). Martian and terrestrial landslides correspond to two distinct scatter plots. The data of terrestrial coefficients of friction from: Evans et al. (1989, 1994), Hewitt (1988, 1998), Mudge (1965), Nicoletti and Sorriso-Valvo (1991), Philip and Ritz (1999), Shreve (1966).

water in unsaturated landslides (Goguel, 1978), or (4) acoustic fluidization (Melosh, 1979).

On the graph showing the landslide volumes and the coefficient of friction (Fig. 11), terrestrial and Martian landslides correspond to two distinct scatter plots. Martian landslides have the same range of coefficient of friction $(0.1-0.3)$ as terrestrial rock avalanches (Table 1, Fig. 11) and differ from the terrestrial ones only by the magnitude of the volume. The low coefficients of friction are also supported by the low slope angle of the Valles Marineris landslide deposits (Table 1) which are lower than $5^{\circ}$. These physical features, long run-out and low slope angle deposits, involve a fluidization mechanism or a basal decollement layer. Recent numerical simulations trying to explain the long run-out of Martian landslides indicate that neither Bingham rheology, nor acoustic fluidization, nor a frictional rheology corresponds to Martian landslides (Harrison and Grimm, 2003) because the final geometry of the 
models is different from the observations. The explanation for large mobility of terrestrial rock avalanches and Valles Marineris landslides is not unanimously accepted as yet.

The most cited rock avalanche similar to Martian landslides is the Sherman landslide (Lucchitta, 1978, 1979). Triggered by an earthquake, this rock avalanche occurred in 1962 on the Sherman glacier in Alaska (Shreve, 1966). The shape of the landslide deposit and the morphologic features display similarities with debris aprons at the toe of several Martian landslides. On a vertical view, the deposit of the landslide has a lobate shape and shows longitudinal divergent ridges as Martian debris aprons (Fig. 12). The origin of the longitudinal ridges is unknown. The long-runout of this landslide was first explained by a mechanism implying a layer of trapped air under the landslide. A basal layer of melted ice from the overlaying glacier is also a possibility. On Mars, mechanism with implying a cushion of atmosphere is improbable because of the low atmospheric pressure. On the other hand, the presence basal layers of melted ice, the role of low amount on liquid water or acoustic fluidization are possible assumptions.

The largest landslide mobilities are located within the widest canyons of Valles Marineris (Fig. 13). Indeed, Gangis Chasma (7.92), Ophir Chasma (7.2) and Melas Chasma (6.21) display the greatest average mobility. If the mobility is related to fluidization mechanisms, there is a relationship between the probable amount in volatile of the widest zone of Valles Marineris and the mobility of the landslides within these zones.
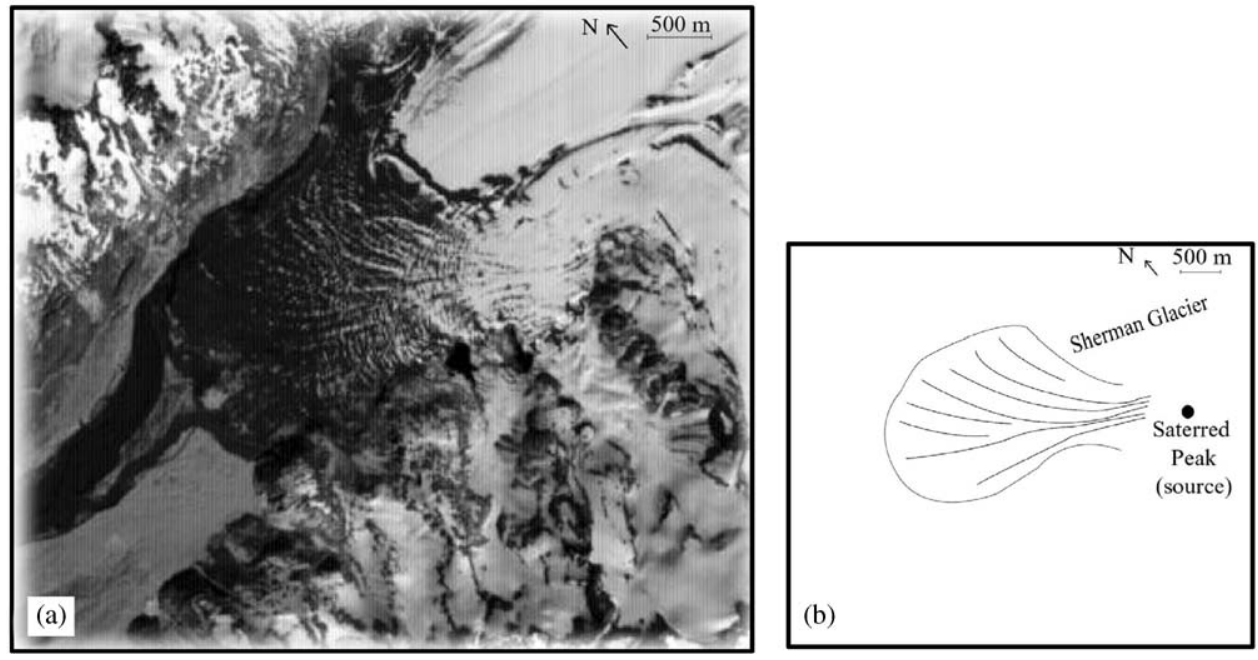

Fig. 12. (a) Part of the Advanced Spaceborne Thermal Emission and Reflection Radiometer (ASTER) band $1(0.52-0.6 \mu \mathrm{m})$ scene over Alaska on 27 January 2001. The landslide deposit covers a part of the glacier Sherman with a lobated shape. (b) Location of the landslide deposit and the landslide source on a sketch of the ASTER scene. The Saterred Peak is located at $60^{\circ} 32^{\prime} \mathrm{N}, 145^{\circ} 06^{\prime} \mathrm{W}$.

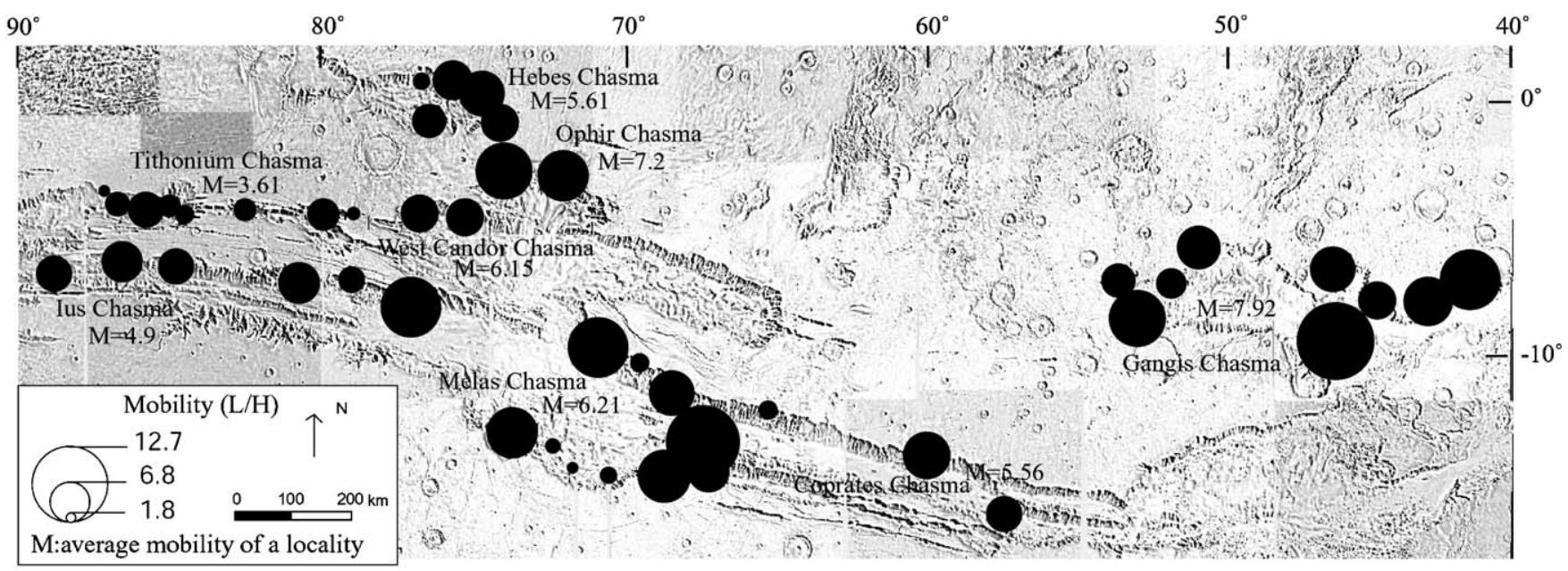

Fig. 13. Distribution of the landslide mobility within Valles Marineris. The diameters of the circles are proportional to the mobility (the runout length $(L)$ relative to the vertical drop $(H)$ ). The average mobility $(M)$ is computed for each locality. 


\section{Discussion}

\subsection{Possible origin of volume deficits}

Every landslide studied here has a volume deficit. The largest deficits occur for landslides located within enclosed canyons. Two hypotheses can explain these volume deficits: (1) The deficits result from material transports after the landslide event or (2) the deficits result from the porosity of the landslide source. The first hypothesis can be easily rejected because there is no evidence of material exportation at the surface of the landslides and because the largest deficits occur within enclosed canyons. Generally, the porosity of landslide deposits is larger than the porosity of the landslide source (Dikau et al., 1996). This is the result from of the re-organization of the slide particles during the landslide event. The material of the Martian landslide deposits has certainly a residual porosity, so the porosity of the material of the landslide source is larger than the volume deficit. The volume deficits are lower bounds for the porosity of the landslide source.

It is generally assumed that the porosity of the Martian regolith decreases exponentially with depth starting from values around $50 \%$ at the surface to values lower than $5 \%$ at $8 \mathrm{~km}$ depth (Clifford and Parker, 2001). So the average porosity of an $8 \mathrm{~km}$ high profile of Martian upper crust material is around $30 \%$. The volume deficits or the lower band values of porosity for 27 landslides are lower than this value. However, 19 landslides whose among which 5 are located within the Hebes Chasma enclosed canyon, have porosity larger than this average value. The lower porosity deduced from volume balances for these 19 landslides is larger than the values of packing arrangements for uniformly sized $(36 \%)$ spheres which is a maximum value obtained by grain arrangement (Pye, 1994). So, it is possible that the value of porosity results from the existence of cavities inside coherent material. These results are in agreement with the predicted strengths of Valles Marineris wallslopes from topographic data which imply fracturing rocks (Schultz, 2002).

This large-scale porosity is either filled up by atmosphere, ice or liquid water. The first assumption implies that there is no water in the first $8 \mathrm{~km}$ of the Martian regolith around the equatorial though system. Although the ground water around this area has been lost by the activity of the outflow channels and by escape to the atmosphere (Carr, 1996), it is difficult to assume that outflows have dried to a depth of eight kilometers of upper crust material. For the second possibility, the kind of porosity previously brought to the fore would imply that the materials in the landslide area have ice lenses as it was previously proposed by Lucchitta (1987). After the landslide event, these ice lenses would have been sublimed and the landslide deposit would display thermokarstic degradations like pits and troughs. But, available MOC images of landslide deposits do not display these kinds of features. Furthermore, according to the hypothesis of ice presence in abundance within the VM wallslopes, the slopes would have typical convex pattern of ice-rich wallslopes like in the middle latitudes on Mars (Mangold and Allemand, 2001) and VM does not display these features. The last assumption of a partial filling of the porosity by water is more probable (partial filling up is used because the shallow part of the regolith was probably dry). The hypothesis is in agreement with the fluidization shape of the debris aprons and the occurrence of the landslides with debris aprons within the widest parts of Valles Marineris which have a more important amount in volatiles at time formation of the canyons (Peulvast et al., 2001). The large mobility of the landslides of Valles Marineris is perhaps explained by this amount of water within the source material.

\subsection{Implications for the geology of Valles Marineris}

The distribution of the parameters of the landslides within Valles Marineris brings to the fore some features of the equatorial trough system. There are correlations between the widest zones of Valles Marineris, the occurrence of the landslides with debris aprons and also the mobility of the landslides. The widest zones like Melas Chasma, would contained a larger amount of volatiles than the other zones of Valles Marineris at time of their formation. This hypothesis is supported by the distribution of the largest mobility of the lobated ejecta around Valles Marineris (Peulvast et al., 2001). Either debris aprons developed in the widest canyons because they had enough space to flow, either there is a correlation between the presence of debris aprons and the possible presence of volatiles in the regolith at the landslide time.

Lastly, we have observed that the largest material deficits occur within the enclosed and semi-enclosed canyons of Valles Marineris (Hebes Chasma, Ophir Chasma and Gangis Chasma). At the canyon scale, these enclosed troughs suggest deficits of material (Carr, 1996). Different models for the origin of these depressions have been proposed among which thermokarstic processes by fusion of interstitial ice or karstic processes by dissolution of carbonate (Spencer and Fanale, 1990). These processes have produced cavities in the wallslope material, so large porosities in the upper crust material. We observe in this study that at the landslides scale, the volume balance displays larger deficits within the enclosed canyons than within other canyons. These results so suggest that the material of the upper crust around the enclosed canyon have larger porosities supporting the possible scenario of karstic or thermokarstic processes at the origin of these canyons. 


\section{Conclusion}

This study reveals that Valles Marineris landslide morphology depends on the factor of confinement of canyons. The chaotic morphologies emplace in narrow canyon whereas landslides with debris aprons occurred in unconfined canyons particularly in the widest part of Valles Marineris. The computing of the landslide volume from MOLA data has revealed that the deposited volumes of individual Valles Marineris landslides reached up to $5000 \mathrm{~km}^{3}$. The landslide volume balances show volume deficits, the largest of which are located within enclosed-canyons. This observation suggests a large porosity of the landslide source in agreement with the hypothesis of a karstic origin of the enclosed-canyons. The large porosities of the landslide source can be filled up by volatiles within the wallslopes of Valles Marineris. The fluidization patterns (large mobility and debris aprons) of the landslide deposits are in agreement with the presence of volatiles within the wallslopes of Valles Marineris at landslide time.

\section{References}

Banerdt, W.B., Golombek, M.P., Tanaka, K.L., 1992. Stress and tectonics on mars. In: Kieffer, H.H., Jakosky, B.M., Snyder, C.W., Matthews, M.S. (Eds.), Mars. University of Arizona Press, Tucson, pp. 249-297.

Boyce, M., Roddy, D.J., Craddock, R., 1996. The origin of Martian fluidized ejecta: The requirement for water in the subsurface. In: Bulletin of the American Astronomical Society, vol. 28. p. 1059.

Carr, M.H., 1996. Water on Mars. Oxford University Press, New York, 229p.

Clifford, S.M., Parker, T.J., 2001. Evolution of the Martian hydrosphere. Icarus 154, 40-79.

Chow, V.T., 1959. Open-channel Hydraulics. McGraw-Hill, New York, 150p.

Dikau, R., Brunsden, D., Schrott, L., Ibsen, M.-L. (Eds.), 1996. Landslide Recognition. Wiley, Chichester, 274p.

Evans, S.G., Clague, J.J., Woodsworth, G.J., Hungr, O., 1989. The Pandemonium Creek Rock Avalanche, British Columbia. Can. Geotech. J. 26, 427-446.

Evans, S.G., Hougr, O., Enegren, E.G., 1994. The Avalanche Lake rock avalanche, Mackenzie Mountains Northwest Territories, Canada: description, dating, and dynamics. Can. Geotech. J. 31, 749-768.

Harrison, H.P., Grimm, R.E., 2003. Rheological constraints on Martian landslides. Icarus 163, 347-362.

Hewitt, K., 1988. Catastrophic Landslide deposits in the Karakoram Himalaya. Science 242, 64-67.

Hewitt, K., 1998. Catastrophic landslides and their effects on the Upper Indus streams, Karakoram Himalaya, northen Pakistan. Geomorphology 26, 47-80.

Goguel, J., 1978. Scale-dependent rockslide mechanisms, with emphasis on the role of pore fluid vaporization. In: Voight, B.
(Ed.), Rockslides and Avalanches, 1. Natural Phenomena. Elsevier, Amsterdam, pp. 693-705.

Head, J.W., Greeley, R., Golombek, M.P., Hartmann, W.K., Hauber, E., Jaumann, R., Masson, P., Neukum, G., Nyquist, L.E., Carr, M.H., 2001. Geological processes and evolution. Sci. Rev. 96, 263-292.

Laberg, J.S., Vorren, T.O., 2000. The Traenadjupet slide offshore Norway-morphology, evacuation and triggering mechanisms. Marine Geol. 71, 95-114

Legros, F., 2002. The mobility of long-runout landslides. Eng. Geol. 63, 301-331.

Lucchitta, B.K., 1978. A large landslide on Mars. Geol. Soc. Am. Bull. 89, 1601-1609.

Lucchitta, B.K., 1979. Landslides in Valles Marineris, Mars. J. Geophys. Res. 84, 8097-8113.

Lucchitta, B.K., 1987. Valles Marineris, Mar: wet debris flows and ground ice. Icarus 72, 411-429.

Mangold, N., Allemand, P., 2001. Topographic analysis of features related to ice on Mars. Geophys. Res. Lett. 28, 407-410.

McCauley, J.F., 1978. Geologic map of the Coprates Quadrangle of Mars, scale 1:5,000,000. U.S. Geol. Survey MisC Inv. Series Map I-897

McEven, A.S., 1989. Mobility of large rock avalanches: Evidence from Valles Marineris, Mars. Geology 17, 1111-1114.

Melosh, J.H., 1979. Acoustic fluidization: A new geologic process. J. Geophys. Res. 84, 7513-7520.

Morgan, B.A., Wieczorek, G.F., Campbell, R.H., Gori, P.L., 1997. Debris-Flow Hazards in Areas Affected by the June 27, 1995 Storm in Madison County, USGS Open-File Report 97-438, Virginia.

Mudge, M.R., 1965. Rockfall-Avalanche and Rockslide-Avalanche Deposits at Sawtooth Ridge, Montana. Geol. Soc. Amer. Bull. 76, 1003-1014.

Nedell, S.S., Squyres, S.W., 1987. Origin and evolution of the layered deposits in the Valles Marineris, Mars. Icarus 70, 409-441.

Nicoletti, P.G., Sorriso-Valvo, M., 1991. Geomorphic controls of the shape and mobility of rock avalanches. Geol. Soc. Amer. Bull. 103, $1365-1373$

Peulvast, J.P., Mége, D., Chiciak, J., Costard, F., Masson, P.L., 2001. Morphology, evolution and tectonics of Valles Marineris wallslopes (Mars). Geomorphology 37, 329-352.

Philip, H., Ritz, J.-F., 1999. Gigantic paleolandslide associated with active faulting along Bogd Fault (gobi-Altay, Mongolia). Geology 27 (3), 211-214.

Pye, K., 1994. Sediment Transport and Depositional Processes. Blackwell Scientific Publication, Oxford, 397p.

Schultz, R.A., 2002. Stability of rock slopes in Valles Marineris Mars. Geophys. Res. Lett. 29 (19), 1932.

Shreve, R.L., 1966. Sherman Landslide. Alaska. Science 154, 1639-1643.

Smith, D.E., Zuber, M.T., Frey, H.V., Garvin, J.B., Head, J.W., Muhleman, D.O., Pettengill, G.H., Phillips, R.J., Solomon, S.C., Zwally, H.J., Banerdt, W.B., Duxbury, T.C., Golombek, M.P., Lemoine, F.G., Neumann, G.A., Rowlands, D.D., Aharonson, O., Ford, P.G., Ivanov, A.B., McGovern, P.J., Abshire, J.B., Afzal, R.S., Sun, X., 2001. Mars Orbiter Laswr Altimeter (MOLA): Experiment summary after the first year of global mapping of Mars. J. Geophys. Res. 106, 23,689-23,722.

Spencer, J.R., Fanale, F.P., 1990. News models for the origin of Valles Marineris closed depressions. J. Geophys. Res. 95, 14301-14313. 